\title{
Flexible Prices and the Business Cycle*
}

\author{
Fabrice Collard ${ }^{\dagger}$ and Harris Dellas ${ }^{\ddagger}$
}

MS: 07-427

\begin{abstract}
Business cycles models with flexible prices face two major empirical challenges. One regards observed output dynamics: The positive, short run, autocorrelation in GNP growth; and the hump-shaped, trend-reverting output response to transitory shocks (Cogley and Nason, 1995). The other regards the alleged persistent decline in employment following a positive technology shock (Galí, 1999). No determinate model with flexible prices has so far been able to address all of the Cogley-Nason-Galí challenges. We show that the standard RBC model can do so if it contains a signal extraction problem involving permanent and temporary supply shocks.
\end{abstract}

JEL class: E1

Keywords: RBC, Cogley-Nason, Galí, Signal Extraction, Investment

\footnotetext{
${ }^{*}$ We would like to thank Lars Hansen, Tim Kehoe, Jim Nason as well as two anonymous referees for valuable comments. Dellas is grateful to Ecoscientia Stiftung for its generous support.

${ }^{\dagger}$ CNRS-GREMAQ, Manufacture des Tabacs, bât. F, 21 allée de Brienne, 31000 Toulouse, France. Tel: (33-5) 61-12-85-42, Fax: (33-5) 61-22-55-63, email: fabrice.collard@univ-tlse1.fr, Homepage: http://fabcol.free.fr

${ }^{\ddagger}$ Department of Economics, University of Bern, CEPR, IMOP. Address: VWI, Schanzeneckstrasse 1, P.O. Box 8573, CH 3001 Bern, Switzerland. Tel: (41) 31-631-3989, Fax: (41) 31-631-3992, email: harris.dellas@vwi.unibe.ch, Homepage: http://www.vwi.unibe.ch/amakro/dellas.htm
} 


\section{Introduction}

The RBC model has enjoyed a great deal of success in accounting for important aspects of macroeconomic fluctuations (see King and Rebelo, 2000, for an evaluation). Nonetheless, success has been far from complete, and a number of critical weaknesses remain. Prominent among them has been its inability to match two important properties of output dynamics. First, the positive, short run, autocorrelation in GNP growth. And second, the hump-shaped, trend-reverting output response to transitory shocks (Cogley and Nason, 1995). This failure stems from the fact that the standard RBC model lacks an effective, endogenous, mechanism for the amplification and propagation of shocks.

An obvious way for trying to improve the performance of the RBC model along this dimension is by incorporating various sources of real inertia. Capital (or investment) adjustment costs, labor adjustment costs, variable capital utilization, habit persistence and financial frictions have been some of the most prominent ones. Cogley and Nason themselves discuss labor and capital adjustment costs (see also Burnside et al., 1993). They argue that capital adjustment costs do not do the job. And that while labor adjustment costs may help with the output autocorrelation, this mechanism requires implausible large transitory shocks in order to match the trend reverting component in output. Burnside and Eichenbaum, 1996, argue that variable capital utilization can help account for the autocorrelation in output growth. But like the capital and labor adjustment costs, this mechanism cannot help capture the response of output to the trend reverting component. Rotemberg and Woodford also address the Cogley-Nason findings as well as the co-movements of the predictable components of several macroeconomic variables. They fail to come up with a convincing specification that can capture these patterns and also do not address the issue of the effects of the trend reverting component. Finally Luo and Young, 2006, examine the Cogley-Nason criticism in the context of an RBC model with rational inattention a la Sims. They show that while incorporating rational inattention can provide an additional internal propagation mechanism and generate higher variance of forecastable movements in output, it does not manage to resolve the $\mathrm{RBC}$ problems. It is thus fair to claim that no existing $\mathrm{RBC}$ model has managed to meet the challenges raised by Cogley and Nason.

The RBC model has also been challenged on the basis of the conditional relationship 
between productivity and employment. Galí has argued that in response to a positive technology shock, employment shows a persistent decline. Hence, the empirical correlation between employment and productivity as well as that between employment and output conditional on technology shocks is negative. While this finding has been challenged by, among others, Chari et al., 2005, this issue remains controversial, which means that proponents of flexible price models cannot yet afford to ignore it. Attempts to account for this finding in models with flexible prices involve using various types of adjustment costs on consumption (habit persistence), investment( such as implementation lags in the adoption of new technology, time-to-implement, Hairault et al., 1997, or time-to-plan, Christiano and Todd, 1996), low substitutability of domestic and foreign goods in the context of international trade (Collard and Dellas, 2007).

The objective of this paper is to propose an inertial mechanism that can help the RBC model match the observed output (Cogley-Nason) and employment (Galí) dynamics following supply shocks. As argued above in the literature review, these two sets of findings have been dealt with by separate literatures. And moreover, only a subset of the Cogley-Nason criticisms has been addressed. Our proposed mechanism involves a signal extraction problem emanating from confusion between transitory and permanent supply shocks. Unlike the standard RBC model where agents are assumed to be able to "promptly" and accurately identify the type of shocks that have occurred, we assume that they may not. Allowing for a meaningful signal extraction problems alters significantly the dynamic properties of the model as the response of the economy under imperfect information can be quite different from that under perfect information ${ }^{1}$. Learning typically leads to hump-shaped responses as agents react "cautiously" initially and make adjustments along the way as their knowledge of their environment improves. While hump shapes are known to obtain under learning and price rigidity (Dellas, 2006) to the best of our knowledge, the case of flexible prices has not been explored. This is actually quite remarkable as the original Kydland and Prescott, 1982, formulation, involved a distinction between (almost) permanent and transitory shocks and learning

\footnotetext{
${ }^{1}$ There exists some other work that has examined the implications of signal extraction problems for the properties of general equilibrium models. For instance, Cooley and Hansen, 1996, do so in the context of the Lucas model, but they do not address the issues discussed here as their interest is on monetary misperceptions. The most ambitious attempt so far to model signal extraction a la Lucas in general equilibrium models is Lorenzoni, 2006. But this is a model without capital and also does not address the dynamic properties of the model which is the subject of Cogley-Nason and Galí.
} 
about the unobserved state of the economy. ${ }^{2}$ This feature was dropped from subsequent versions of the RBC model as it was not deemed important for generating reasonable unconditional moments.

We show that signal extraction is sufficient to generate responses that look like those in the data when the agents are confused between a temporary investment specific shock (Greenwood et al., 2000) and a permanent Solow residual shock. For different menus of shocks, imperfect information may not be sufficient to account for all the criticisms without the help of additional inertial features (such as investment adjustment costs). Nonetheless, we also find that imperfect information is necessary for the RBC model to have good dynamic properties.

The rest of the paper is organized as follows. The model is described in section 1. Section 2 discusses the calibration. Section 3 updates the Cogley-Nason and Galí findings and examines the ability of the RBC model to match them.

\section{The model}

The benchmark model is the standard RBC model. We consider an economy that contains a large number of dynastic households and a large number of firms. Firms produce a homogeneous final product that can be either consumed or used for investment purposes. Firms own their capital stock and hire labor supplied by the households. Households own the firms. In each and every period three perfectly competitive markets operate, the markets for consumption goods, labor services, and financial capital in the form of firms' shares. Household preferences are characterized by the lifetime utility function:

$$
E_{t} \sum_{s=0}^{\infty} \beta^{s} \log \left(C_{t+s}\right)-\theta_{h} \frac{h_{t+s}^{1+\omega}}{1+\omega}
$$

where $0<\beta<1$ is a constant discount factor, $C_{t}$ is consumption in period $t, h_{t}$ is the fraction of total available time devoted to productive activity in period $t . \theta_{h}>0$ is a utility parameter. We solve the problem using a central planner who determines hours, consumption and capital accumulation by maximizing the household's utility function subject to the resource constraint

$$
C_{t}+I_{t}=Y_{t}
$$

\footnotetext{
${ }^{2}$ The response of the industrial economies to the first oil shock in 1974 as well as the more recent debate about the new economy in the late 1990s are but two important examples of a signal extraction problem involving temporary vs permanent supply and supply vs demand shocks.
} 
where $I_{t}$ denotes investment and $Y_{t}$ is output. Output is produced by means of capital and labor services, using a constant returns to scale technology represented by the following Cobb- Douglas production function:

$$
Y_{t}=\left(u_{t} K_{t}\right)^{\alpha}\left(\Gamma_{t} h_{t}\right)^{1-\alpha} \text { with } 0<\alpha<1
$$

where $u_{t}$ denotes variable capital utilization. $\Gamma_{t}$ denotes neutral technological progress, which is assumed to follow a random walk with drift.

Investment is used to form physical capital, which accumulates according to:

$$
K_{t+1}=Q_{t} I_{t}+\left(1-\delta\left(u_{t}\right)\right) K_{t} \text { with } 0 \leqslant \delta(\cdot) \leqslant 1, \delta^{\prime}(\cdot)>0, \delta^{\prime}(\cdot)>0
$$

where $\delta$ is the constant physical depreciation rate. Implicit in the capital accumulation process is that it is subject to a depreciation in use as captured by the increasing and convex function $\delta(\cdot)$ (see e.g. Greenwood et al., 1988, Burnside and Eichenbaum, 1996, or King and Rebelo, 2000 among others).

We follow Greenwood et al., 2000, and Fisher, 2006 and consider investment specific technology improvement, modeled by $Q_{t}$. This factor captures the current state of the technology for producing equipment and therefore accounts for investment-specific technological change, which is assumed to affect equipment only. Greenwood et al., 2000, argue that variations in $Q$ can account for about $30 \%$ of business fluctuations in the post war II period in the US, while Greenwood et al., 1997, conclude that this feature can explain about $60 \%$ of US postwar growth in output per man-hour. Fisher, 2006, shows that investment specific shocks account for up to $67 \%$ of output volatility in the post 1982 era. Greenwood et al. 2000 assume a stationary process for $Q$ while Fisher, 2006, argues that it follows a random walk. ${ }^{3}$ We do not take a formal stand on this and rather assume that $Q$ has indeed a permanent and a transitory component.

The neutral technological process takes the form

$$
\log \left(\Gamma_{t}\right)=\log (\gamma)+\log \left(\Gamma_{t-1}\right)+\varepsilon_{\gamma, t}
$$

while the investment specific shock is given by

$$
Q_{t}=V_{t} q_{t}
$$

\footnotetext{
${ }^{3}$ Therefore, the overall growth component in the model is given by $\gamma_{t} V_{t}^{\frac{\alpha}{1-\alpha}}$.
} 
where, following Fisher, 2006

$$
\begin{aligned}
& \log \left(V_{t}\right)=\log (\nu)+\log \left(V_{t-1}\right)+\varepsilon_{v, t}, \nu \geqslant 1, \\
& \log \left(q_{t}\right)=(1-\rho) \log (\bar{q})+\rho \log \left(q_{t-1}\right)+\varepsilon_{q, t}, \text { with }|\rho|<1
\end{aligned}
$$

and

$$
\left(\begin{array}{l}
\varepsilon_{\gamma, t} \\
\varepsilon_{v, t} \\
\varepsilon_{q, t}
\end{array}\right) \rightsquigarrow \mathscr{N}\left(\left(\begin{array}{l}
0 \\
0 \\
0
\end{array}\right),\left(\begin{array}{ccc}
\sigma_{\gamma}^{2} & 0 & 0 \\
0 & \sigma_{v}^{2} & 0 \\
0 & 0 & \sigma_{q}^{2}
\end{array}\right)\right)
$$

\section{Parametrization}

The model is parameterized so that it matches features of the US economy in the post world war II era at a quarterly frequency.

$\beta$, the discount factor is set such that households discount the future at a $5 \%$ annual rate, implying $\beta$ equals 0.988 . The labor supply inverse elasticity is set to $\omega=0$. Therefore, the model assumes indivisible labor supply. The leisure parameter $\nu$ is set such that the households devote $31 \%$ of their total time endowment to productive activities.

\begin{tabular}{|c|c|c|}
\hline \multicolumn{3}{|l|}{ Technology } \\
\hline Capital elasticity of intermediate output & $\alpha$ & 0.3500 \\
\hline Depreciation rate & $\delta$ & 0.0250 \\
\hline Depreciation elasticity & $\bar{u} \delta^{\prime \prime}(\bar{u}) / \delta^{\prime}(\bar{u})$ & 0.1 \\
\hline \multicolumn{3}{|l|}{ Preferences } \\
\hline Discount factor & $\beta$ & 0.988 \\
\hline Labor supply elasticity & $\omega$ & 0.0000 \\
\hline Leisure parameter & $\nu$ & 2.7655 \\
\hline \multicolumn{3}{|l|}{ Shocks } \\
\hline Average rate of growth of $\Gamma$ & $\gamma$ & 1.0040 \\
\hline Average rate of growth of $V$ & $\nu$ & 0.9954 \\
\hline Share of neutral shock in permanent component & $\lambda^{2} \equiv \frac{\sigma_{\gamma}^{2}}{\sigma_{\gamma}^{2}+\alpha^{2} \sigma_{v}^{2} /(1-\alpha)^{2}}$ & 0.8879 \\
\hline
\end{tabular}
The average growth of both neutral $(0.40 \% \text { per quarter })^{4}$ and investment specific $(-0.46 \%$

Table 1: Calibrated Parameters

per quarter) technological progress are borrowed from Fisher, 2006, who estimated them

\footnotetext{
${ }^{4}$ Our numbers differ from those reported in Fisher, 2006 because we do not specify the neutral technological progress in the same way $\left(\Gamma_{t}=A_{t}^{\frac{1}{1-\alpha}}\right)$.
} 
from the data. This led us to set $\gamma=1.0040$ and $\nu=0.9954$, which an average annual growth rate of $1.47 \%$. $\alpha$, the elasticity of the production function with regard to capital, is set such that the model reproduces the US labor share - defined as the ratio of labor compensation to GDP - over the sample period (0.65). This implies a value for $\alpha$ of 0.35. The quarterly depreciation rate, $\delta$, is 0.025 , implying an annual depreciation of about $10 \%$. Following ?, the elasticity of the depreciation rate function is set to 0.1 .

We now specify the structure of information in the case of a signal extraction problem. We assume that agents know they are hit by technology shocks in each and every period. But they are not aware of the type of shock that hit them. More precisely, when hit by a shock, they do not know whether it is permanent or transitory, neither do they know whether this is a neutral or an investment specific shock. Instead they are given two noisy signals, one on output and one on the permanent component. Since both signal are measured with error and are a mix of the 3 shocks, the agents cannot infer the true state of the economy but learn about it gradually using the Kalman filter.

$$
x_{i, t}^{\star}=x_{i, t}^{\mathrm{T}}+\eta_{i, t}
$$

where $x_{i, t}^{\mathrm{T}}$ denotes the true value of signal $i$ and $\eta_{i, t}$ is a noisy process that satisfies $E\left(\eta_{i, t}\right)=0$ for all $t ; E\left(\eta_{i, t} \varepsilon_{\gamma, t}\right)=E\left(\eta_{i, t} \varepsilon_{v, t}\right)=E\left(\eta_{i, t} \varepsilon_{q, t}\right)=E\left(\eta_{i, t} \eta_{i, t} \eta_{j, t}\right)=0$; and

$$
E\left(\eta_{i, t} \eta_{i, k}\right)=\left\{\begin{array}{cc}
\varsigma_{i}^{2} & \text { if } t=k \\
0 & \text { Otherwise }
\end{array}\right.
$$

The parameters pertaining to the process of stochastic shocks remain to be set. We estimate these parameters so as to match a set of impulse responses as derived from a permanent/transitory component decomposition la Cogley and Nason, 1995. We use the simulated moment method to reveal the parameters. More precisely, the parameters are estimated so as to minimize the distance between impulse responses estimated from the data and corresponding impulse responses as obtained from data obtained via simulations of the model. Denoting $\Theta$ the set of parameters to be estimated, this amounts to select $\widehat{\Theta}$ such that it is a solution to

$$
\min _{\Theta}(\widehat{I R F}-\widetilde{I R F}(\Theta))^{\prime} \Omega(\widehat{I R F}-\widetilde{I R F}(\Theta))
$$

where $\widehat{I R F}$ and $\widetilde{I R F}(\Theta)$ respectively denote the impulse response function of output to shock the permanent and the transitory component in the model and in the data. $\Omega$ 
is a weighting matrix which is given by the inverse of the covariance matrix of impulse responses as estimated in the data. Impulse responses in the data are estimated relying on Cogley and Nason, 1995. The empirical analysis updates their empirical findings. We use quarterly U.S. data for the period 1948:I-2002:IV. Output is measured by GDP. Following Galí and Rabanal, 2004, we measure the labor input as hours of all persons in the non-farm business sector. All variables are then expressed in per capita terms, using civilian noninstitutional population aged 16 and over. We estimated a VAR(2) model between output growth $(\Delta y)$ and hours $(h)$ worked. ${ }^{5}$ The simulated impulse responses $\widetilde{I R F}(\Theta)$ are obtained by simulating the model over 20 times. $^{6}$

Omitting constants, the joint behavior of $(\Delta y, h)$ admits the following Wold representation $^{7}$

$$
\left(\begin{array}{c}
\Delta y_{t} \\
h_{t}
\end{array}\right)=C(L)\left(\begin{array}{c}
\mu_{1, t} \\
\mu_{2, t}
\end{array}\right)
$$

where $L$ is the lag operator, $C(L)=I+\sum_{i=1}^{\infty} C_{i} L^{i}$, and where the covariance matrix of $\mu$ is given by $\Sigma$. Given $C(1)$, it is possible to derive a representation of the data in terms of permanent and transitory components of the form

$$
\left(\begin{array}{c}
\Delta y_{t} \\
h_{t}
\end{array}\right)=\Gamma(L)\left(\begin{array}{c}
\varepsilon_{t}^{P} \\
\varepsilon_{t}^{T}
\end{array}\right)
$$

where the covariance matrix of $\left(\varepsilon^{P}, \varepsilon^{T}\right)$ is the identity matrix and $\Gamma(L)=\sum_{i=0}^{\infty} \Gamma_{i} L^{i}$. The $\Gamma$ matrices solve

$$
\begin{cases}\Gamma_{0} \Gamma_{0}^{\prime} & =\Sigma \\ \Gamma_{i} & =C_{i} \Gamma_{0} \text { for } i>0\end{cases}
$$

Note that once $\Gamma_{0}$ is known, all $\Gamma_{i}$ are pinned down by the second set of relations. But, due to the symmetry of the covariance matrix $\Omega$, the first part of the system only pin downs three parameters of $\Gamma_{0}$. One remains to be set. This is achieved by imposing an additional restriction. We impose that the 1,2 element of the long run matrix $\Gamma(1)=\sum_{i=0}^{\infty} \Gamma_{i}$ equals zero, that is, we choose an orthogonalization where the disturbance $\varepsilon^{T}$ has no long run impact on $Y$ (the use of this type of orthogonalization was first proposed by Blanchard and Quah, 1989). Hence, $\varepsilon^{T}$ is labeled as a temporary shock, while $\varepsilon^{P}$ is a permanent one. The covariance matrix of impulse responses is

\footnotetext{
${ }^{5}$ As in Cogley and Nason, 1995, we checked the robustness of our empirical results against changes in the specification of the VAR. We did not find any significant differences.

${ }^{6}$ ? have shown that efficiency gains are negligible for a number of simulations larger than 10 .

${ }^{7}$ Note that $y=\log (Y)$.
} 
obtained by bootstrapping the VAR. ${ }^{8}$ The parameters of the stochastic processes are then estimated so as to match the response of output to a shock to its permanent and transitory component.

We then estimate the persistence parameter, $\rho$, and the volatility, $\sigma_{q}$, of the transitory component of the investment specific shock, the volatility of the overall permanent component, $\sigma_{p}$, and the noise of the signal $\varsigma_{\eta}$. We do not estimate the volatility of the permanent component of the investment specific shock and that of the neutral shock separately for identification issues. Indeed, since we focus on Cogley and Nason puzzle, we do not attempt to identify separately the two shocks driving the permanent component. We therefore just identify the permanent component. The sharing of the volatility between neutral shocks and investment specific shocks is done on the basis of some results by Fisher, 2006. Given that the permanent component of the model takes the form $\Gamma_{t} V_{t}^{\frac{\alpha}{1-\alpha}}$, the overall volatility of its rate of growth is given by $\sigma_{\gamma}^{2}+\frac{\alpha^{2}}{(1-\alpha)^{2}} \sigma_{v}^{2}$. Therefore the neutral shock accounts for a share $\lambda^{2} \equiv \sigma_{\gamma}^{2} /\left(\sigma_{\gamma}^{2}+\frac{\alpha^{2}}{(1-\alpha)^{2}} \sigma_{v}^{2}\right)$ of the overall volatility of the permanent component. Using Fisher's estimation, this led us to set $\lambda^{2}=0.8879$. Therefore, once we have an estimate for the volatility of the permanent component, we can allocate it between the neutral and the investment specific shock. The estimated parameters are reported in Table 2 .

Table 2: Estimated Parameters

\begin{tabular}{lccc}
\hline \hline & & Imp. Info. & Perf. Info \\
\hline Volatility of permanent component & $\sigma_{p}$ & 0.0064 & 0.0026 \\
& & $(9.64 \mathrm{e}-4)$ & $(8.57 \mathrm{e}-5)$ \\
Persistence of investment shock & $\rho$ & 0.4839 & 0.9999 \\
& & $(0.2009)$ & $(0.0071)$ \\
Volatility of investment shock & $\sigma_{\varepsilon}$ & 0.0035 & 0.0006 \\
& & $(0.0048)$ & $(4.56 \mathrm{e}-4)$ \\
Noise on output & \multirow{2}{*}{$\varsigma_{1}$} & 0.0143 & - \\
Noise on perm. comp. & & $(0.0206)$ & \\
& $\varsigma_{2}$ & 0.0119 & - \\
\hline J-Stat & & $(0.0292)$ & \\
\hline \hline
\end{tabular}

\footnotetext{
${ }^{8}$ We used 1000 replications. Following Christiano, Eichenbaum and Evans, 2005, we restrict ourselves to the diagonal part of the matrix.
} 


\section{Results}

Figure 1: Perfect versus Imperfect Information: The Cogley and Nason findings
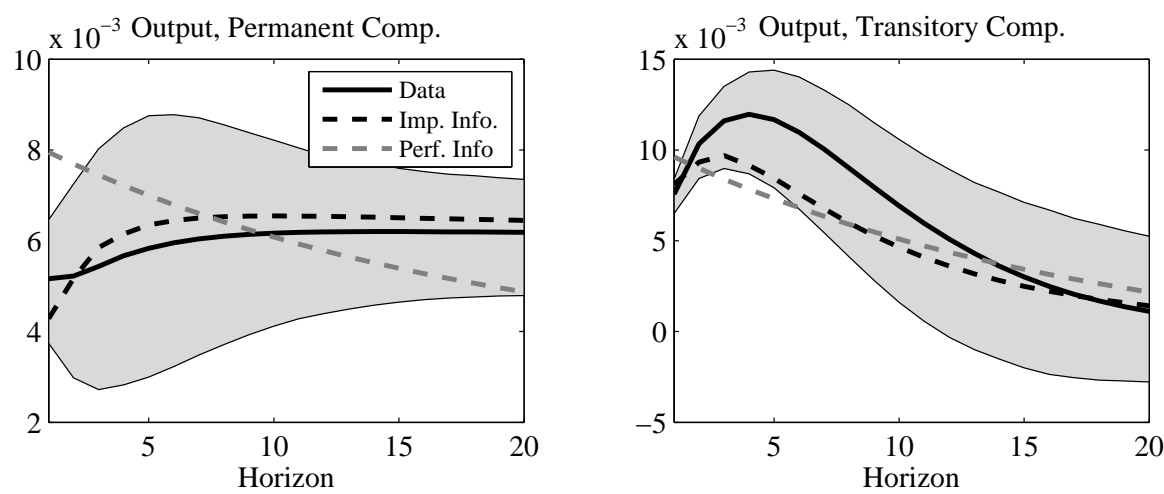

Figure 2: Perfect versus Imperfect Information: Autocorrelation Function

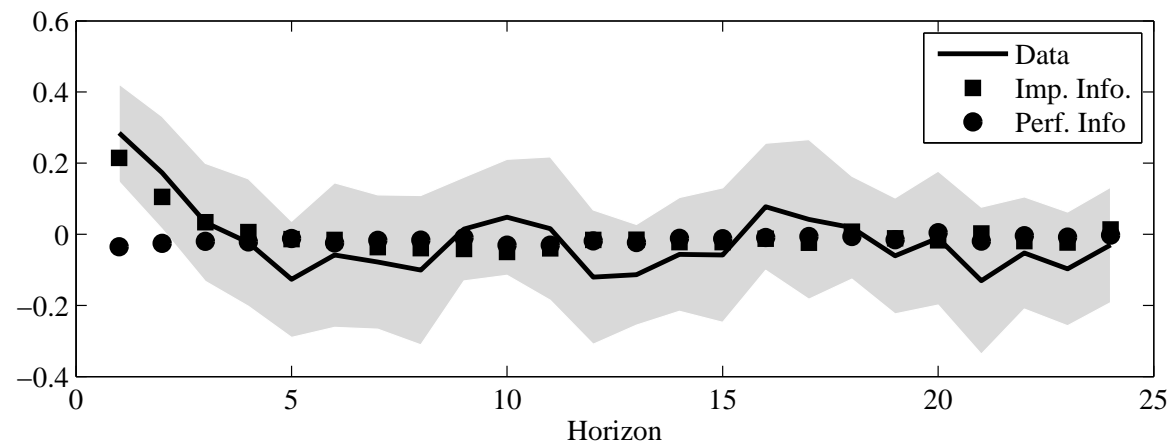

Figure 1 and 2 show the IRFs to a permanent and temporary shock as well as the autocorrelation function in the data and in the model. The shaded area gives the 95\% confidence interval, computed from bootstraps. As can be seen the model is quite successful in matching both the dynamics of output following temporary and permanent shocks and the output growth autocorrelation function.

Figure 3 shows the IRFs of employment in the model and in the data (we have used Gali's approach for identifying the shocks with permanent and temporary effects and constructing the corresponding empirical IRFS). Again the model does quite well, in particular with regard to temporary shocks. For a permanent positive technology shock, the model generates a persistent decline in employment, which is somewhat larger than that observed in the data (mostly on impact). Again the model does not fare well under perfect information.

The signal extraction feature plays a critical role as can be seen by examining the 
Figure 3: Perfect versus Imperfect Information: The Galí finding

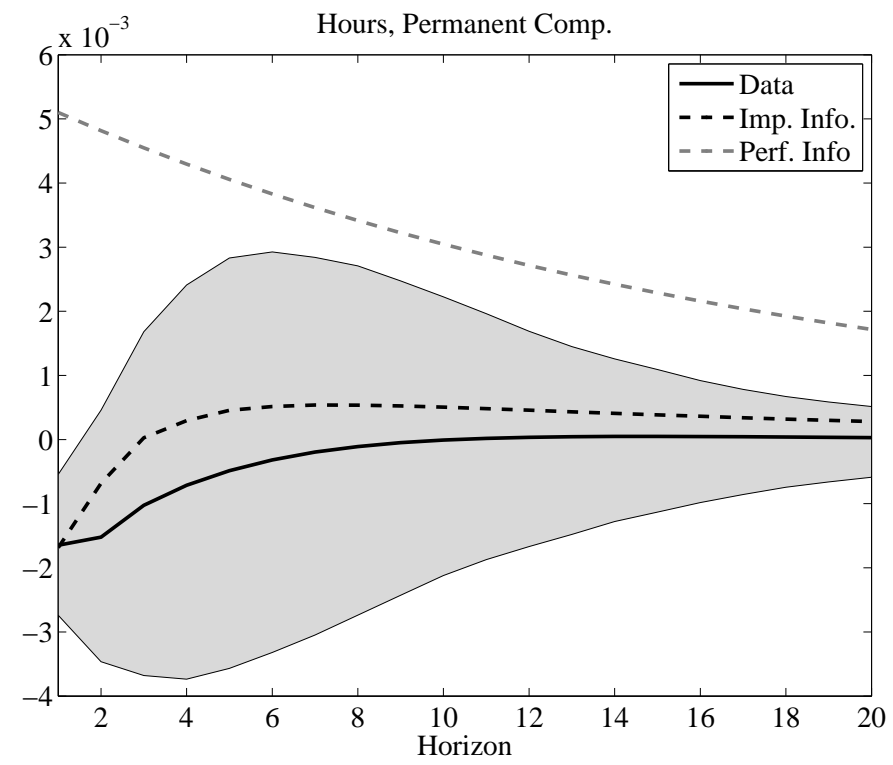

performance of the model in its absence (what we call the "perfect" information case). Several remarks are in order. First of all, signal extraction tends to smooth the permanent component relative to the perfect information case. This can be understood by looking at the way the agents perceive the shocks. For instance, Figure 4 reports the IRF of both shocks following a technology shock. As can be seen from the figure, the

Figure 4: IRF to a neutral technology shock
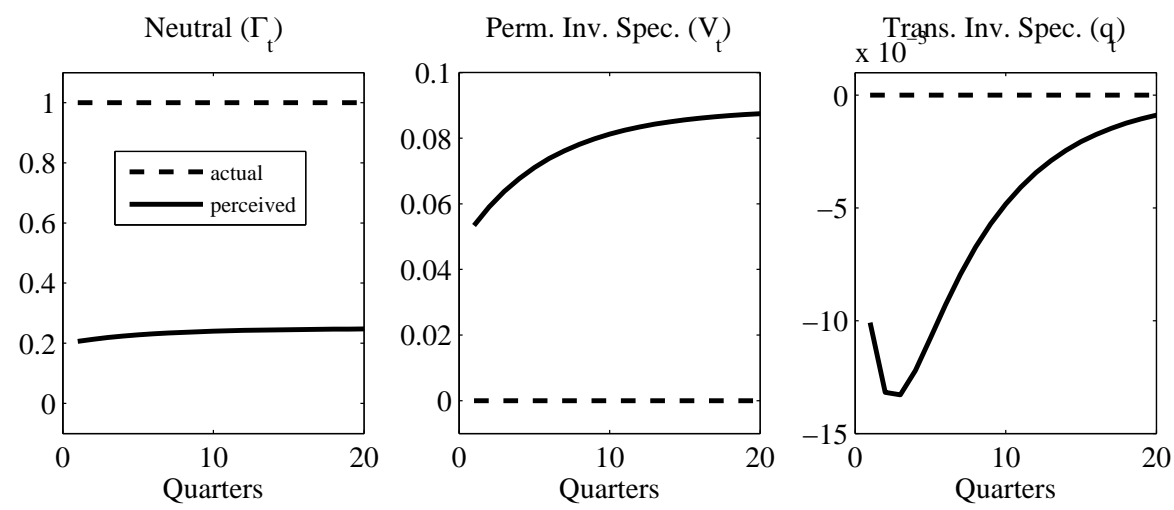

agents tend to underestimate the technology shock in the imperfect information case and attribute part of the observed changes to a perceived negative investment shock. This has two effects. First, the underestimation of the technology shock by itself generates a lower response of output growth and hours worked relative to the perfect information case. And second, the perception of a negative investment specific shock dampens things 
even further. In particular, the negative investment shock drives the response of output further down, and more importantly drives hours worked down. This effect enables the model to reproduce the Galí finding.

Second, as shown in Figure 6, signal extraction generates a hump shape in the perception of the investment shock and a persistent decline in the perceived technology shock.

Figure 5: IRF to a permanent investment shock
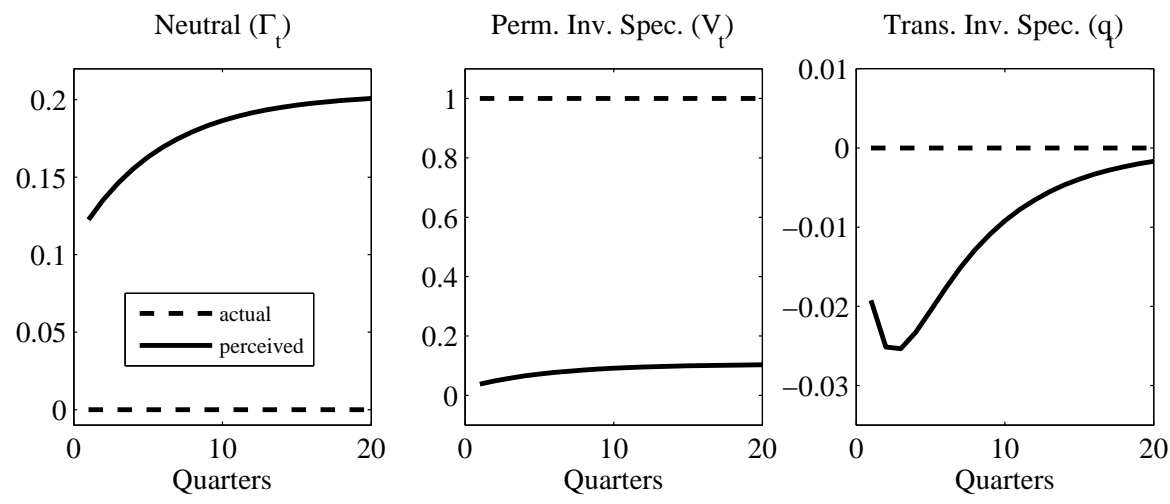

Figure 6: IRF to a transitory investment shock
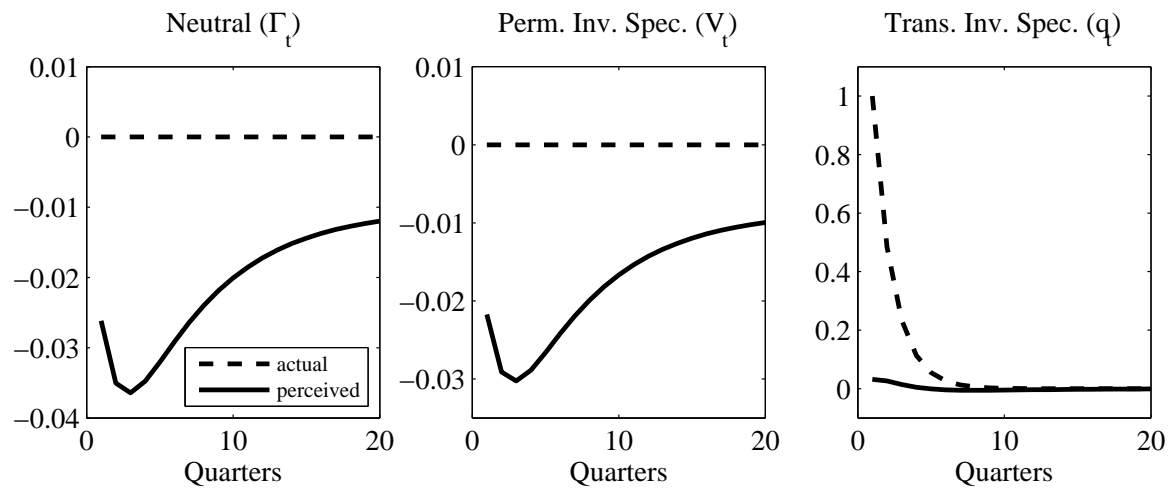

This has important implications for the trend reverting component of output dynamics. The hump shaped response of the $q$ shock is inherited by the response of output growth. This effect is reinforced by the negative perceived technology shock that further slows down output growth in the few first periods following the investment shock. These perceptions about the shocks exert two effects on the dynamics of the model: (i) they smooth the response of output growth relative to the perfect information case, (ii) they create a propagation mechanism that helps generate the hump shape response of output growth and persistence in the autocorrelation function. 
Robustness We have also carried out a robustness analysis with regard to the menu of shocks.

In particular, we have studied the dynamics properties of the model under the specification used originally by Kydland and Prescott, 1982, which involved a signal extraction problem between a temporary and permanent supply (Solow residual) shock. We find that unlike the case considered above where imperfect information was sufficient on its own for generating good dynamic properties, under the Kydland and Prescott specification, it may need to be combined with other inertial features, such as investment adjustment costs, to produce good dynamics. Nonetheless, imperfect information is still an essential factor because without it, the model cannot match the Galí finding.

From these findings we conclude that the signal extraction is essential if the RBC model is to have realistic conditional and unconditional dynamics for output and employment.

\section{Conclusions}

The RBC model has faced two critical empirical challenges during the last years. One regards its inability to generate empirically plausible output dynamics. Cogley and Nason, 1995 have argued that none of the standard modifications to the RBC model can improve its performance along this dimension. At the same time, Galí has argued that the flexible price model supply-shock driven model cannot account for the observed persistent decline in employment following a positive technology shock.

A large literature has taken up pieces and bits of these challenges with partial success. Nonetheless, there exists no version of the RBC in the literature that can satisfy simultaneously the Cogley and Nason and Galí criticism. In this paper we have resurrected the signal extraction problem that appeared in the original Kydland and Prescott, 1982, paper and combined it with investment specific technology improvements (as in Greenwood et al., 2000). We have shown that with these two empirically plausible modifications, the standard RBC becomes capable of addressing both empirical challenges.

\section{References}

Blanchard, O.J. and D. Quah, 1989, The Dynamic Effects of Aggregate Supply and Demand Disturbances, American Economic Review, 79 (4), 655673. 
Burnside, C., and M. Eichenbaum, 1996, Factor-Hoarding and the Propagation of BusinessCycle Shocks The American Economic Review, Vol. 86, (5), 1154-1174.

Burnside, C., M. Eichenbaum, and S. Rebelo, 1993, Labor hoarding and the business cycle, Journal of Political Economy, 101 (2), 245273.

Christiano, L.J., M.,Eichenbaum, and C.L., Evans, 2005, Nominal Rigidities and the Dynamic Effects of a Shock to Monetary Policy, Journal of Political Economy, 113(1), $1-45$.

Christiano, L. and R. Todd, 1996, Time to Plan and Aggregate Fluctuations, Federal Reserve Bank of Minneapolis Quarterly Review, 20 (1), 1427.

Cogley, T. and J.M. H. Nason, 1995, Output Dynamics in RealBusinessCycle Models, American Economic Review, 85 (3), 492511.

Collard, F. and H. Dellas, 2007, Technology Shocks and Employment, Economic Journal, $117,1436-1459$.

Galí, J. and P. Rabanal, Technology Shocks and Aggregate Fluctuations: How Well Does the RBC Model Fit Postwar U.S. Data?, NBER Macroeconomics Annual 2004.

Galí, J., 1999, Technology, Employment, and the Business Cycle: Do Technology Shocks Explain Aggregate Fluctuations?, American Economic Review, 89 (1), 249271. ,

Galí, J., 2003, New Perspectives on Monetary Policy, Inflation, and the Business Cycle, in M. Dewatripont, L. Hansen, and S. Turnovsky, editors, Advances in Economic Theory, Cambridge (MA): Cambridge University Press, pp. 151197.

Greenwood, J., Z. Hercowitz, and P. Krusell, 1997, Long-run implications of investment specific technological change, American Economic Review, 1997, 87 (3), 342392.

Greenwood, J., Z. Hercowitz, and P. Krusell, 2000, The Role of InvestmentSpecific Technological Change in the Business Cycle, European Economic Review, 2000, 44 (1), 91115.

Hairault, J.O., F. Langot, and F. Portier, Time to Implement and Aggregate Fluctuations, Journal of Economic Dynamics and Control, 1997, 22 (1), 109121. 
King, R and S. Rebelo, Resuscitating Real Business Cycles, in J. Taylor and M. Woodford, editors, Handbook of Macroeconomics, Elsevier, 2000.

Kydland, F.E. and E.C. Prescott, Time-to-build and Aggregate Fluctuations, Econometrica, November 1982, 50 (6), 13451370.

Lorenzoni, G., 2006, A Theory of Demand Shocks, mimeo MIT.

Luo, Y. and E. Young, 2006, Rational Inattention and Aggregate Fluctuations, mimeo.

Woodford, M., Imperfect Common Knowledge and the Effects of Monetary Policy, NBER Working Paper 8673, NBER 2001. 